\title{
Transcatheter mitral valve therapy: The event horizon
}

Vinay Badhwar, MD, ${ }^{\mathrm{a}}$ Vinod H. Thourani, MD, ${ }^{\mathrm{b}}$ Gorav Ailawadi, MD, ${ }^{\mathrm{c}}$ and Michael Mack, $\mathrm{MD}^{\mathrm{d}}$
Transcatheter aortic valve replacement has entered the clinical armamentarium mainstream of surgeons and interventional cardiologists in the management of high- and extreme-risk patients with aortic stenosis. Transcatheter mitral valve therapies are closely following suit. A flurry of global innovation, research, and clinical activity over the last 10 years have led to dynamic changes to the technologic landscape. With 1 device commercially approved, and several more in early feasibility studies in the United States with significant equity investments by major device manufacturers, the point of no return for this field of therapy finding its way into daily clinical practice is upon us. The current progress and future development of transcatheter mitral valve repair (TMVr) and transcatheter mitral valve replacement (TMVR) are outlined.

\section{CLINICAL BASIS AND OPPORTUNITY}

The prevalence of mitral regurgitation (MR) remains higher than any other valvulopathy, ${ }^{1,2}$ but up to half of patients with moderate to severe MR are not referred for surgery on the basis of patient or referral preference, comorbid risk, or lack of demonstration of clinical benefit in the case of secondary MR. ${ }^{3}$ Despite excellent results with surgical mitral valve repair in higher-risk elderly populations, comorbidities and degree of heart failure at presentation remain potent predictors of longitudinal outcome. ${ }^{4}$ In addition to morbidity risk, the pathoanatomic difference between primary (degenerative) MR and secondary (functional) MR is recognized as a dichotomizing predictor of postprocedural MR recurrence. Repair still can provide safe and durable correction of secondary MR in certain cases, but inferior-basal ventricular dysfunction and severe tethering are more refined predictors of early recurrence with conventional repair techniques. ${ }^{5}$

Surgical mitral valve repair remains the most effective and durable therapy for patients with primary MR. However, for patients with primary MR who are at prohibitive surgical risk, challenges exist on how to optimally introduce newer, innovative transcatheter alternatives. The best way to adjudicate

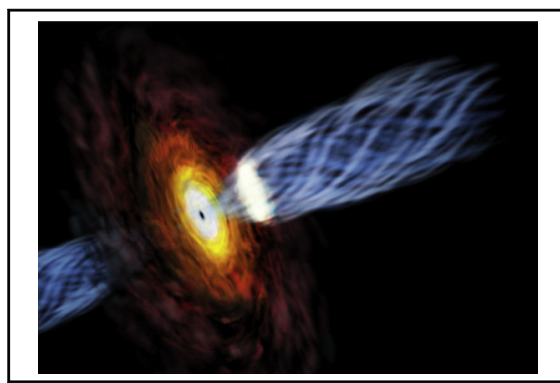

The event horizon for transcatheter mitral therapy to enter clinical practice is upon us.

\section{Central Message}

Transcatheter technology for mitral repair or replacement has reached active clinical investigation in the United States. The most developed devices are highlighted.

See Article page 319

See Editorial Commentaries page 328 and 336.

innovative surgical and interventional mitral therapies is through a robust collaboration within a well-functioning heart team that includes not only a cardiac surgeon and interventional cardiologist but also an imaging specialist. Because many of the devices currently in development or in early feasibility trials require surgical involvement, embracing this opportunity to collaboratively engage is imperative.

There is a growing population of patients with primary and secondary MR underserved by surgical therapy because of comorbid risk. This has led to a tremendous activity of device development. Currently, more than 25 unique transcatheter device companies have been capitalized and are matriculating through various levels of preclinical and clinical investigation. The market opportunity and inevitability of success for 1 or several of these devices can be measured by the unprecedented industry investment into the mitral space to the tune of more than $\$ 2.5$ billion dollars in 2015 alone.

The conventional pathway of device development involves preclinical bench and large animal testing to document mechanical safety and reasonable procedural efficacy. This is followed by a first-in-human (FIH) implant and an early feasibility study (EFS) on up to 15 to 20 patients to document safety, determine device performance, and define the optimal patient population for pivotal trials. The majority of EFSs have been performed outside of the United States, often followed by clinical trials targeted at Conformité Européene (CE) mark approval and then finally a 
pivotal trial in the United States targeted at approval for commercial use from the Food and Drug Administration (FDA). In the past, as with transcatheter aortic valve replacement, this process has taken up to 9 years from FIH to US FDA approval. Recently, the FDA has taken the prescient step to approve EFS investigation for at least 4 of the transcatheter mitral devices to be performed in the United States, potentially shortening the time that these devices will receive regulatory approval for the US market.

Unlike the straightforwardness in the management of aortic stenosis with aortic valve replacement, the mitral valve is far more complex with a multitude of disease states requiring numerous repair or replacement techniques. As such, transcatheter mitral repair or replacement devices will need to address issues of access, device delivery, and anchoring to mitigate embolization, paravalvular leaks, and left ventricular outflow tract obstruction. The pipeline of technology is dynamic, but a few devices have shown some early promise. The current therapies for TMVr and TMVR will be presented, and those projected as most likely to be clinically available within the next decade will be highlighted.

\section{TRANSCATHETER MITRAL VALVE REPAIR}

The current transcatheter mitral repair device leader is the MitraClip (Abbott Vascular, Santa Clara, Calif). Much of what we know of the patient population with transcatheter mitral repair, the development of the mitral heart team, the importance of imaging, and the nuances of device delivery and navigation has been established through the clinical introduction of this device. The MitraClip device is delivered in an antegrade trans-septal approach across the atrial septum from the femoral vein to achieve anterior-posterior edge-to-edge direct leaflet approximation. Although imperfect as a solution for all patients, the MitraClip device clearly has demonstrated a good safety profile and reasonable 5year outcomes for primary MR. ${ }^{6}$ Since the MitraClip attained the CE mark, more than 25,000 procedures have been performed worldwide and more than 10,000 procedures in 2015 alone. The MitraClip device received FDA approval for commercial use in patients with primary MR with prohibitive surgical risk on October 24, 2013. Since then, more than 4000 commercial procedures have been performed in the United States, and more than 2500 procedures in 2015 , with $85 \%$ being used in primary MR. A Society of Thoracic Surgeons/American College of Cardiology transcatheter valve therapy database analysis of the first 564 cases performed through August 2014 revealed the average patient age was 83 years, with a median Society of Thoracic Surgeons predicted risk of mortality for repair and replacement of $7.9 \%$ and $10.0 \%$, respectively. ${ }^{7}$ The majority of patients had documented severe frailty, prior cardiac surgery, and end-stage heart failure symptoms. The procedural success was $91.8 \%$, with a 30 -day operative mortality of $5.8 \%$, a 3 -day average length of stay, and a home discharge rate of
$80 \%$. The site-reported overall success at reducing MR to $2+$ or less was $93 \%$ before leaving the hospital.

Although these results are admirable from a safety and short-term efficacy perspective for primary MR, we must keep in mind that the bar set for MR reduction at moderate or less by the Endovascular Valve Edge-to-Edge Repair Study (EVEREST) II trial does not compare with what is achievable surgically. ${ }^{6}$ Buzzatti and co-authors ${ }^{8}$ from Milan recently reported their experience with 223 consecutive cases and found that residual $2+$ MR or greater after MitraClip device use was associated with worse follow-up outcomes, including survival, symptom relief, and MR recurrence. Before applying this technology to lower-risk cohorts with primary MR, its longitudinal efficacy must be proven through a well-constructed randomized trial of homogeneous groups comparing it with mitral repair in experienced centers. ${ }^{9,10}$ For now, the MitraClip device seems to be the leading option for patients with primary MR and prohibitive surgical risk.

The primarily ventricular disease of secondary MR has proven to be a different clinical entity. Careful patient selection is required to attain durable results and avoid short-term MR recurrence with mitral repair. ${ }^{5}$ The Clinical Outcomes Assessment of the MitraClip Percutaneous Therapy trial has been designed as a primary heart failure trial enrolling 430 patients in 85 US centers randomized to guideline-directed medical therapy including resynchronization as appropriate to guideline-directed medical therapy plus the MitraClip device. As of January 2016, enrollment surpassed 331 patients with expected completion targeted for June 2016. An important lesson learned from the trial to date includes the outcome benefits of guidelinedirected medical therapy on correction of MR. The primary end points of survival and hospital readmission for heart failure, and secondary functional outcome end points are expected in late 2017 or early 2018. Device development in the mitral space does not appear to be waiting for the results of the Clinical Outcomes Assessment of the MitraClip Percutaneous Therapy trial. Table 1 illustrates several TMVr devices in various stages of development.

One of the earliest concepts introduced was to use the coronary sinus as a conduit to deliver a remodeling device in an attempt at reducing secondary MR. Despite ease of delivery, the obvious anatomy incongruences led to the abandonment of many of the early devices. The Carillion device (Cardiac Dimensions Inc, Kirkland, Wash) is the last of the coronary sinus indirect annuloplasty methods to make it to clinical approval in Europe. However, despite achieving the CE mark, the results of the recent clinical trial have been unremarkable. ${ }^{11}$ Of the 53 intention-to-treat patients enrolled after screening, only 36 received an implant with questionable success, including 7 of 17 failures due to transient circumflex coronary compromise, thus imperiling the clinical use of this device without substantial modifications. 
TABLE 1. Transcatheter mitral valve repair technologies

\begin{tabular}{|c|c|c|c|c|c|}
\hline Company & Product & Primary target & Approach & Regulatory & Status \\
\hline $\begin{array}{l}\text { Abbott Vascular (Santa } \\
\text { Clara, Calif) }\end{array}$ & MitraClip & Primary MR & Antegrade, direct leaflet & CE mark, FDA approved & $\begin{array}{l}\text { US commercial use for } \\
\text { prohibitive surgical ris }\end{array}$ \\
\hline Abbott Vascular & MitraClip & Secondary MR & Antegrade, direct leaflet & CE mark & US pivotal trial \\
\hline $\begin{array}{l}\text { HeartWare (Framingham, } \\
\text { Mass)/Valtech (Or } \\
\text { Yehuda, Israel) }\end{array}$ & Cardioband & Secondary MR & Antegrade, direct annular & CE mark & US EFS \\
\hline $\begin{array}{l}\text { NeoChord Inc (St Louis } \\
\text { Park, Minn) }\end{array}$ & NeoChord & Primary MR & $\begin{array}{l}\text { Retrograde (TA), direct } \\
\text { leaflet }\end{array}$ & CE mark & $\begin{array}{l}\text { Outside of the United } \\
\text { States only }\end{array}$ \\
\hline $\begin{array}{l}\text { Cardiac Dimensions Inc } \\
\text { (Kirkland, Wash) }\end{array}$ & Carillion & Secondary MR & Antegrade, coronary sinus & CE mark & $\begin{array}{l}\text { Outside of the United } \\
\text { States only }\end{array}$ \\
\hline $\begin{array}{l}\text { Mitralign (Tewksbury, } \\
\text { Mass) }\end{array}$ & Mitralign & Secondary MR & $\begin{array}{l}\text { Retrograde (TF), direct } \\
\text { annular }\end{array}$ & $\begin{array}{l}\text { Outside of the United } \\
\text { States early feasibility }\end{array}$ & CE Mark Trial \\
\hline $\begin{array}{l}\text { Guided Delivery Systems } \\
\text { (Santa Clara, Calif) }\end{array}$ & Accucinch & Secondary MR & $\begin{array}{l}\text { Retrograde }(\mathrm{TF}) \text {, direct } \\
\text { annular }\end{array}$ & $\begin{array}{l}\text { Outside of the United } \\
\text { States early feasibility }\end{array}$ & CE Mark trial \\
\hline $\begin{array}{l}\text { Ample Medical (Foster } \\
\text { City, Calif) }\end{array}$ & PS3 Magnecath & Secondary MR & Antegrade, direct annular & $\begin{array}{l}\text { Outside of the United } \\
\text { States early feasibility }\end{array}$ & CE Mark trial \\
\hline $\begin{array}{l}\text { Phoenix Cardiac } \\
\text { (Northbrook, Ill) }\end{array}$ & BACE Device & Secondary MR & $\begin{array}{l}\text { Epicardial (TA), external } \\
\text { constraint }\end{array}$ & $\begin{array}{l}\text { Outside of the United } \\
\text { States early feasibility }\end{array}$ & CE Mark trial \\
\hline $\begin{array}{l}\text { Cardiosolutions Inc (West } \\
\text { Bridgewater, Mass) }\end{array}$ & Mitra-Spacer & Secondary MR & $\begin{array}{l}\text { Retrograde (TA), direct } \\
\text { leaflet }\end{array}$ & Preclinical, FIH & $\begin{array}{r}\text { Outside of the United } \\
\text { States and US EFS }\end{array}$ \\
\hline $\begin{array}{l}\text { Harpoon Medical } \\
\text { (Baltimore, Md)/ } \\
\text { Edwards Lifesciences } \\
\text { (Irvine, Calif) }\end{array}$ & Harpoon & Primary MR & $\begin{array}{l}\text { Retrograde (TA), direct } \\
\text { leaflet }\end{array}$ & Preclinical, FIH & $\begin{array}{l}\text { Outside of the United } \\
\text { States EFS }\end{array}$ \\
\hline $\begin{array}{l}\text { Millipede, LLC (Ann } \\
\text { Arbor, Mich) }\end{array}$ & Millipede & Secondary MR & Antegrade, direct Annular & Preclinical, FIH & $\begin{array}{l}\text { Outside of the United } \\
\text { States EFS }\end{array}$ \\
\hline $\begin{array}{l}\text { QuantumCor (Lake } \\
\text { Forest, Calif) }\end{array}$ & QuantumCor & Secondary MR & $\begin{array}{l}\text { Retrograde (TA), direct } \\
\text { annular }\end{array}$ & Preclinical, FIH & In development \\
\hline HeartWare/Valtech & V-Chordal & Primary MR & $\begin{array}{l}\text { Retrograde (TA), direct } \\
\text { leaflet }\end{array}$ & Preclinical & In development \\
\hline $\begin{array}{l}\text { TransCardiac } \\
\text { Therapeutics (Atlanta, } \\
\text { Ga) }\end{array}$ & MitraFlex & Primary MR & $\begin{array}{l}\text { Retrograde (TA), direct } \\
\text { leaflet }\end{array}$ & Preclinical & In development \\
\hline $\begin{array}{l}\text { Coramaze (Essen, } \\
\text { Germany) }\end{array}$ & MitraMaze & Primary MR & Antegrade, direct leaflet & Preclinical & In development \\
\hline
\end{tabular}

Transcatheter mitral repair technologies listed in order of progression with regulatory and clinical milestones. Primary MR: primary degenerative MR; secondary MR: secondary functional MR; antegrade: mitral access via trans-septal puncture and left atrial access; retrograde: mitral access via the left ventricle. $M R$, Mitral regurgitation; $C E$, Conformité Européene; FDA, Food and Drug Administration; EFS, early feasibility study (15-20 patients); $T A$, transapical; $T F$, transfemoral; $F I H$, first-in-human.

The Cardioband device (Valtech, Or Yehuda, Israel) is an antegrade trans-septal device similar to the MitraClip device, but with a very different approach to MR reduction. ${ }^{12}$ Primarily targeting secondary MR, the Cardioband delivers an actuating rivet into each trigone along with 12 to 16 spaced anchors while delivering a flexible posterior annuloplasty band. The annuloplasty is then dynamically reduced under transesophageal echocardiography to achieve $\mathrm{MR}$ reduction. The device has achieved the CE mark and is scheduled to begin a US trial in 2016. If the device is proven effective in clinical trials, many surgeons and cardiologists have projected a clinical trial using combined devices that address annular remodeling with leaflet-based repair. The Cardioband and MitraClip devices may lend themselves as candidates for this form of future investigation.
The NeoChord device (NeoChord Inc, St Louis Park, Minn) uses a transapical mini left thoracotomy access to deliver polytetrafluoroethylene chord(s) to the leading edge of the flailed leaflet in patients with primary MR. The device includes an actuating device that grasps the leaflet, and upon monitor feedback of capture, the straightforward trigger mechanism deploys a single chord looped at the leaflet that is exteriorized via the ventricular apex where it is tied. The device has the ability to deploy multiple chordae. Early experience with the CE mark-approved device appears feasible, but experience remains limited. ${ }^{13}$ Of note, the similar Harpoon device (Harpoon Medical, Baltimore, $\mathrm{Md}$ ) delivers a transapical chord to the body of the leaflet with a securing anchor on the atrial side of the leaflet. Multiple chords can be delivered through the $14 \mathrm{~F}$ 
transapical sheath. The device has been tested in preclinical studies and has just completed its FIH milestone with more than 10 EFS patients outside of the United States.

The Mitralign device (Mitralign, Tewksbury, Mass) is a device using the principles of a Kay annuloplasty to deliver 2 pledgeted polytetrafluoroethylene chords to the mitral annulus at an interval distance and then cinches them together with a locking tie mechanism. Performed fully percutaneously via a retrograde transfemoral approach, the 14F steerable catheter enables dual chordal deployment. Preliminary results appear promising from the EFS in Europe such that a European clinical trial is under way. ${ }^{14}$

The Accucinch device (Guided Delivery Systems, Santa Clara, Calif) involves a similar retrograde transfemoral route and delivery concept to the Mitralign device, but it attempts to achieve a full posterior annuloplasty from trigone to trigone posteriorly using cables to perform a reduction annuloplasty. European EFSs appear to demonstrate adequate safety but with complexities of MR reduction associated with the amount of deployment in the subvalvular space. ${ }^{15}$

The Millipede device (Millipede LLC, Ann Arbor, Mich) is a trans-septal circumferentially anchored full nitinol ring annuloplasty system. After more than 50 preclinical animal implants, the device has been implanted in 6 patients outside of the United States, including use in the tricuspid position, with promising early safety and functional outcomes as of January 2016.

The Mitra-Spacer device (Cardiosolutions Inc, West Bridgewater, Mass) is a transapical buoy-like device that aims to provide a sealing surface at the level of mitral coaptation. After approximately 150 preclinical animal experiments, a total of 10 combined cases in the United States and outside of the United States have been attempted as of January 2016 with mixed results. Several interesting TMVr ideas at various stages of preclinical or funding success have had early achievements but remain in nascent development (Table 1).

\section{TRANSCATHETER MITRAL VALVE REPLACEMENT}

Unlike TMVr, the challenges of deploying and anchoring a functional prosthetic device into the MV annulus amid the intact subvalvular apparatus is altogether more complex. Although innovation continues, current TMVR delivery systems remain large (ie, 32F-42F), and the majority require a transapical retrograde approach to the mitral valve. Nevertheless, a number of devices that are now beginning EFS investigation have promising preliminary results. As of January 2016, the total human experience with TMVR implantation surpassed 50 cases, with half of those performed in the United States. However, robust preclinical and FIH data combined with the unprecedented capital investment in these devices have enabled feasibility trials for TMVR to begin in Europe (Table 2). By the end of
2015, 4 devices were permitted to begin human US EFS investigation (Figure 1).

The Tendyne device (Abbott Vascular) is a transapically delivered and potentially fully retrievable trileaflet porcine pericardial valve with an impermeable nitinol skirt that has a prominent cuff positioned to rest on the intertrigonal aorto-mitral curtain. ${ }^{16}$ The atrial component has a large 30- to $43-\mathrm{mm}$ cuff. It is anchored by an apical tether that is secured with a locking pad mechanism at the ventricular apex. In some TMVR devices, capturing the leaflets in primary MR is used to stabilize the valve while preventing systolic anterior motion. This is less important in secondary MR with dilated ventricles where the aorto-mitral conversion angle is more obtuse. The Tendyne is an intraannular valve that does not specifically capture the leaflets, and thus the primary clinical target is patients with functional secondary MR with left ventricular dilatation and prohibitive surgical risk. The Tendyne achieved FIH in October 2014. It is one of the devices to be granted a 15patient US EFS, with the first US implant performed on April 14, 2015. Early experience has been free of left ventricular outflow tract obstruction. As of January 2016, a total of 23 of 30 global EFS cases have been completed, including 5 European compassionate use cases. The EFS is expected to close by March of 2016, at which time a CE mark clinical trial will begin in Europe. Abbott Vascular is currently in discussions with the FDA on a US trial design, which is expected to begin by early 2017 .

The Tiara valve (Neovasc Inc, Richmond, BC) is a transapically delivered $32 \mathrm{~F}$ sheathless system with a self-dilating tip to facilitate ventricular entry. The trileaflet bovine pericardial valve is mounted on a nitinol frame with an atrial skirt positioned on the inter-trigonal aorto-mitral curtain. This is accompanied by 3 subvalvular anchors, 1 on each trigone to facilitate leaflet capture and 1 at the level of P2. The valve comes in 4 sizes of $30 \mathrm{~mm}, 35 \mathrm{~mm}, 40 \mathrm{~mm}$, and $45 \mathrm{~mm}$ that correspond to internal diameters of $25 \mathrm{~mm}, 30 \mathrm{~mm}, 34.3 \mathrm{~mm}$, and $38.5 \mathrm{~mm}$, respectively. They achieved FIH status in February 2014, and the 8patient single-center experience as of November $2015 \mathrm{had}$ been performed with no 30 -day operative mortality. ${ }^{17}$ The US EFS also started in 2015.

The CardiaQ valve (Edwards Lifesciences, Irvine, Calif) has been designed to potentially facilitate both trans-septal antegrade and transapical retrograde delivery. This highprofile trileaflet bovine pericardial valve is mounted on a self-expanding frame. Their second-generation version has strived to mitigate mobility with left ventricular anchors that engage the annulus and chords for secure load distribution. The FIH implant was achieved via a trans-septal approach in June 2012 and transapically in May 2014. As of June 2015, 9 patients underwent implantation outside of the United States, 7 of whom had successful deployment. ${ }^{18}$ 
TABLE 2. Transcatheter mitral valve replacement technologies

\begin{tabular}{|c|c|c|c|c|c|}
\hline Company & Product & Primary target & Approach & Regulatory & Status \\
\hline Abbott Vascular (Abbott Park, Ill) & Tendyne & Secondary MR & Retrograde (TA) & FIH & $\begin{array}{l}\text { CE mark trial, } \\
\text { US EFS }\end{array}$ \\
\hline $\begin{array}{l}\text { Neovasc Inc (Richmond, British } \\
\text { Columbia, Canada) }\end{array}$ & Tiara & Primary/secondary MR & Retrograde (TA) & FIH & $\begin{array}{l}\text { CE mark trial, } \\
\text { US EFS }\end{array}$ \\
\hline $\begin{array}{l}\text { Edwards LifeSciences (Irvine, } \\
\text { Calif) }\end{array}$ & CardiaQ & Primary/secondary MR & $\begin{array}{l}\text { Retrograde (TA), } \\
\text { antegrade }\end{array}$ & FIH & $\begin{array}{l}\text { CE mark trial, } \\
\text { US EFS }\end{array}$ \\
\hline $\begin{array}{l}\text { Medtronic Inc (Minneapolis, } \\
\text { Minn) }\end{array}$ & Twelve & Secondary MR & Retrograde (TA) & FIH & $\begin{array}{l}\text { Outside of the } \\
\text { United States EFS }\end{array}$ \\
\hline Edwards Lifesciences & Fortis & Secondary MR & Retrograde (TA) & FIH & $\begin{array}{l}\text { Outside of the United } \\
\text { States EFS halted }\end{array}$ \\
\hline $\begin{array}{l}\text { MValve Technologies } \\
\text { (Herezeliya, Israel) Boston } \\
\text { Scientific (Marlborough, Mass) }\end{array}$ & MValve & Primary/secondary MR & Retrograde (TA) & FIH & $\begin{array}{l}\text { Outside of the United } \\
\text { States EFS }\end{array}$ \\
\hline $\begin{array}{l}\text { Cephea (San Jose, Calif)/Abbott } \\
\text { Vascular }\end{array}$ & Cephea & Secondary MR & Antegrade & Preclinical & In development \\
\hline HeartWare/Valtech & Cardiovalve & Secondary MR & Retrograde (TF) & Preclinical & In development \\
\hline MitrAssist (Caesarea, Israel) & MitrAssist & Primary/secondary MR & Retrograde (TA) & Preclinical & In development \\
\hline HighLife Medical (Irvine, Calif) & HighLife MVR & Secondary MR & $\begin{array}{l}\text { Retrograde (TA), } \\
\text { antegrade }\end{array}$ & Preclinical & In development \\
\hline Emory University (Atlanta, Ga) & MitraCath & Secondary MR & Retrograde (TA) & Preclinical & In development \\
\hline $\begin{array}{l}\text { Micro Interventional Devices } \\
\text { (Newtown, Pa) }\end{array}$ & EndoValve & Secondary MR & antegrade & Preclinical & In development \\
\hline NCSI (Laguna Hills, Calif) & Navigate TMVR & Secondary MR & $\begin{array}{l}\text { Retrograde (TA), } \\
\text { antegrade }\end{array}$ & Preclinical & In development \\
\hline
\end{tabular}

Primary MR: primary degenerative MR; secondary MR: secondary functional MR; antegrade: mitral access via trans-septal puncture and left atrial access; retrograde: mitral access via the left ventricle. $M R$, Mitral regurgitation; $T A$, transapical; $F I H$, first-in-human; $C E$, Conformité Européene; $E F S$, early feasibility study (15-20 patients); $T F$, transfemoral. Transcatheter mitral replacement technologies listed in order of progression with regulatory and clinical milestones.

There were 2 intraprocedural deaths and 2 in-hospital deaths. The US EFS is scheduled to commence in 2016.

The Fortis device (Edwards Lifesciences) is a transapically delivered bovine pericardial single size valve that has a unique paddle mechanism to capture the native leaflets. By capturing the anterior leaflet, it minimizes the risk of outflow tract obstruction, and by incorporating the leaflets, it creates an annular seal to mitigate paravalvular leak. The FIH was achieved in February 2014, and since then, 20 patients underwent implantation as part of a European EFS. ${ }^{19}$ The majority of these cases were for secondary functional MR, and the 30-day mortality approached $40 \%$. A US EFS was started in early 2015 with 8 patients and $100 \%$ success in device implantation. However, in May 2015, the trial was stopped because of the discovery of early valve thrombosis in 2 patients.

The Twelve valve (Medtronic Inc, Minneapolis, Minn) is a transapically delivered $27-\mathrm{mm}$ bovine trileaflet valve that uses a differential stent design that dually separates prosthesis seating and sealing from valve function (Figure 1). The prosthesis comes in 3 outer stent sizes of $43 \mathrm{~mm}$, $46 \mathrm{~mm}$, and $50 \mathrm{~mm}$. As of November 2015, 8 patients underwent the procedure as part of an ongoing EFS enrolling in Krakow, Poland, of whom 7 had a successful deployment with two 30-day mortalities.
The MValve (MValve Technologies, Herezeliya, Israel) is a different platform, insomuch that it is not a valve, but a transapically deployed docking device that is designed to universally fit other existing transcatheter prostheses. In particular, its design has had preclinical experience with the Lotus transcatheter aortic valve (Boston Scientific, Marlborough, Mass). The MValve achieved its FIH implant in October 2015 deploying a transmitral anchoring mechanism within a calcified rheumatic valve that enabled deployment and docking of the Lotus valve as a valve in the docking procedure. Several TMVR concepts remain in preclinical status that will bear watching in the coming years (Table 2).

\section{FUTURE PERSPECTIVES}

The role of surgical therapy in the management of mitral valve disease will remain the dominant treatment modality for primary MR for at least the next 10 years. Expertise in the performance of complex open, minimally invasive, or robotic mitral valve repair will remain critical for patients with primary MR of low to even high risk because this can be regularly delivered with durable outcomes and negligible mortality. ${ }^{20,21}$ However, as our patient cohorts become increasingly more complex and transcatheter mitral therapies more facile, the day when this will become a daily clinical reality will soon be upon us. 

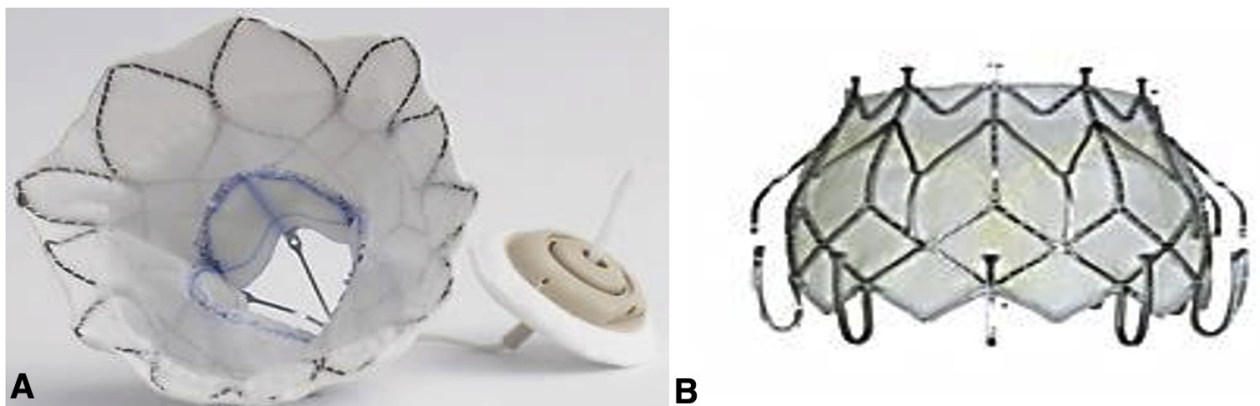

B

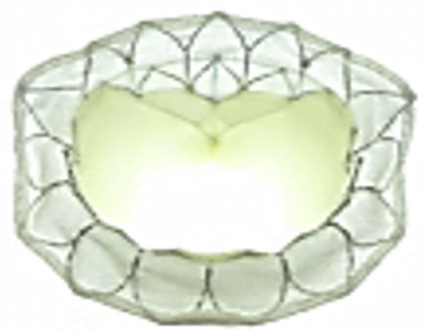

C

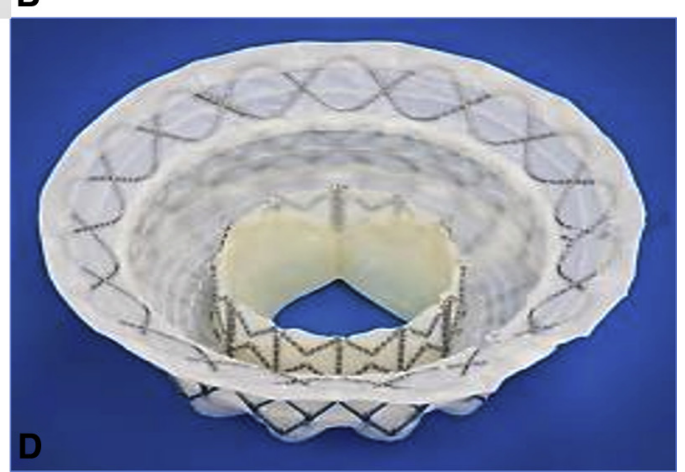

FIGURE 1. Examples of current TMVR devices under active clinical investigation. A, The Tendyne (Abbott Vascular, Santa Clara, Calif). B, The CardiaQ Valve (Edwards Lifesciences, Irvine, Calif). C, The Tiara Valve (Neovasc, Richmond, BC). D, The Twelve Valve (Medtronic Inc, Minneapolis, Minn).

An event horizon is defined by astrophysical relativity as the boundary around a singularity or black hole where nothing can escape-the point of no return. Until this year, this boundary remained theoretical. After many years of effort, using new telescopic imaging technology, scientists from around the world collaborated to visualize and clearly define the event horizon of the galaxy's largest black hole for the first time and published their findings in the December 2015 issue of Science. ${ }^{22}$ After many years in development, the recent global technologic collaborations introducing TMVr and TMVR have brought us to the defined event horizon for transcatheter mitral valve therapy.

\section{CONCLUSIONS}

Surgeons have a unique opportunity to cement existing collaborations with their interventional, imaging, and heart failure colleagues to expand their portfolio of excellence in surgical and transcatheter mitral repair and replacement. This will soon enable the team-based mitral specialist to be facile in safely transitioning patients from open mitral surgery to TMVr or TMVR as most appropriate for durable long-term outcomes.

\section{Conflict of Interest Statement}

V.B.: Abbott Vascular Advisory Board (uncompensated). V.H.T.: Advisory Board and Research Grants: Edwards LifeSciences, Medtronic Cardiovascular, Abbott Vascular, and St Jude Medical. G.A.: Consultant: Abbott Vascular, Edwards LifeSciences, St Jude Medical, Mitralign, and AtriCure. M.M.: Edwards Lifesciences Steering Committee
Partner Trial (travel expenses paid for committee meetings), Abbott Vascular Co-Principal Investigator, Clinical Outcomes Assessment of the MitraClip Percutaneous Therapy Trial (uncompensated).

\section{References}

1. Nkomo VT, Gardin JM, Skelton TN, Gottdiener JS, Scott CG, EnriquezSarano M. Burden of valvular heart diseases: a population-based study. Lancet. 2006;368:1005-11.

2. Lloyd-Jones D, Adams RJ, Brown TM, Carnethon M, Dai S, De Simone G, et al. American Heart Association Statistics Committee and Stroke Statistics Subcommittee. Heart disease and stroke statistics - 2010 update: a report from the American Heart Association. Circulation. 2010;121:e46-215.

3. Mirabel M, Iung B, Baron G, Messika-Zeitoun D, Détaint D, Vanoverschelde JL, et al. What are the characteristics of patients with severe, symptomatic, mitral regurgitation who are denied surgery? Eur Heart J. 2007;28:1358-65.

4. Badhwar V, Peterson ED, Jacobs JP, Xie H, Brennan MJ, O'Brien SM, et al. Longitudinal outcome of isolated mitral repair in older patients: results from 14,604 procedures performed from 1991 to 2007. Ann Thorac Surg. 2012;94:1870-9.

5. Kron IL, Hung J, Overbey JR, Bouchard D, Gelijns AC, Moskowitz AJ, et al. Predicting recurrent mitral regurgitation after mitral valve repair for severe ischemic mitral regurgitation. J Thorac Cardiovasc Surg. 2015;149:752-61.

6. Feldman T, Kar S, Elmariah S, Smart SC, Trento A, Siegel RJ, et al. Randomized comparison of percutaneous repair and surgery for mitral regurgitation: 5-year results of EVEREST II. J Am Coll Cardiol. 2015;66:2844-54.

7. Sorajja P, Kar S, Stebbins A, Vemulapalli S, Lim DS, Thourani V, et al. Outcomes of the initial experience with commercial transcatheter mitral valve repair in the US-a report from the STS/ACC TVT Registry. Presented at: American College of Cardiology 64th Annual Scientific Sessions, San Diego, California, March 15, 2015.

8. Buzzatti N, De Bonis M, Denti P, Barili F, Schiavi D, Di Giannuario G, et al What is a "good" result after transcatheter mitral repair? Impact of $2+$ residual mitral regurgitation. J Thorac Cardiovasc Surg. 2016;151:88-96.

9. Anyanwu AC, Adams DH. Evaluating catheter-based mitral valve therapies: lessons learned and future directions. J Am Coll Cardiol. 2015;66:2855-9.

10. Stone GW, Adams DH, Abraham WT, Kappetein AP, Généreux P, Vranckx P, et al. Clinical trial design principles and endpoint definitions for transcatheter mitral valve repair and replacement: part 2: endpoint definitions: a consensus 
document from the Mitral Valve Academic Research Consortium. Eur Heart J. 2015;36:1878-91.

11. Siminiak T, Wu JC, Haude M, Hoppe UC, Sadowski J, Lipiecki J, et al. Treatment of functional mitral regurgitation by percutaneous annuloplasty: results of the TITAN trial. Eur J Heart Fail. 2012;14:931-8.

12. Taramasso M, Guidotti A, Cesarovic N, Denti P, Addis A, Candreva A, et al. Transcatheter direct mitral annuloplasty with Cardioband: feasibility and efficacy trial in an acute preclinical model. EuroIntervention. November 18, 2015 [Epub ahead of print].

13. Colli A, Manzan E, Zucchetta F, Sarais C, Pittarello D, Gerosa G. Feasibility of anterior mitral leaflet flail repair with transapical beating-heart neochord implantation. JACC Cardiovasc Interv. 2014;7:1320-1.

14. Nickenig G, Hammerstingl C. The Mitralign transcatheter direct mitral valve annuloplasty system. EuroIntervention. 2015;11(Suppl W):W62-3.

15. Gooley RP, Meredith IT. The Accucinch transcatheter direct mitral valve annuloplasty system. EuroIntervention. 2015;11(Suppl W):W60-1.

16. Perpetua EM, Reisman M. The Tendyne transcatheter mitral valve implantation system. Eurolntervention. 2015;11(Suppl W):W78-9.
17. Cheung A, Webb J, Verheye S, Moss R, Boone R, Leipsic J, et al. Short-term results of transapical transcatheter mitral valve implantation for mitral regurgitation. J Am Coll Cardiol. 2014;64:1814-9.

18. Sondergaard L, Brooks M, Ihlemann N, Jonsson A, Holme S, Tang M, et al. Transcatheter mitral valve implantation via transapical approach: an early experience. Eur J Cardiothorac Surg. 2015;48:873-8.

19. Abdul-Jawad Altisent O, Dumont E, Dagenais F, Sénéchal M, Bernier M, O'Connor K, et al. Initial experience of transcatheter mitral valve replacement with a novel transcatheter mitral valve: Procedural and 6-month follow-up results. J Am Coll Cardiol. 2015;66:1011-9.

20. Woo YJ, Goldstone AB. The contemporary evolution of mitral valve surgery. $J$ Thorac Cardiovasc Surg. 2016;151:7-9.

21. Suri RM, Durani JA, Mihaljevic T, Chitwood RW, Murphy DA, Trento A, et al. Mitral valve repair using robotic technology: safe, effective and durable. $J$ Thorac Cardiovasc Surg. 2016;151:1450-4.

22. Johnson MD, Fish VL, Doeleman SS, Marrone DP, Plambeck RL, Wardle JFC, et al. Resolved magnetic-field structure and variability near the event horizon of Sagittarius A. Science. 2015;350:1242-5.

\title{
EDITORIAL COMMENTARY
}

\section{Ode to the mitral valve: "The times are a changin""}

\author{
W. Randolph Chitwood, Jr, MD, FACS, FRCS (Eng), FACC
}

From the Department of Surgery, Brody School of Medicine, East Carolina University, Greenville, NC.

Disclosures: The author is a consultant for Direct Flow Medical, Inc, and is a coprincipal investigator for the Edwards Lifesciences, Inc. Transform Trial.

Received for publication April 11, 2016; accepted for publication April 12, 2016; available ahead of print May 24, 2016.

Address for reprints: W. Randolph Chitwood, Jr, MD, FACS, FRCS (Eng), FACC, 146 East Longmeadow Rd, Greenville, NC 27858 (E-mail: chitwoodw@ecu.edu).

J Thorac Cardiovasc Surg 2016;152:336-7

0022-5223/\$36.00

Copyright (C) 2016 by The American Association for Thoracic Surgery

http://dx.doi.org/10.1016/j.jtcvs.2016.04.031

As Bob Dylan put it so well in 1964, "The times are a changing." This article assures cardiac surgeons that "an event horizon" is blatantly true today, as many new mitral valve devices are threatening our well-proven surgical valve operations. ${ }^{1}$ Badwahr et al have reviewed comprehensively the most up-to-date information regarding the transcatheter mitral valve therapies that are in play today and have given us a hint of what "could/may/will" be the future. This paper gives us direction and is the clarion call for cardiac surgeons to become engaged in this rapidly evolving parade.

Large clinical trials already have defined safety and efficacy for both transcatheter aortic valve replacement (TAVR) and mitral clip technology. Recent 2-year Placement of AoRTic TraNscathetER Valves (PARTNER II) clinical trial data showed in intermediate-risk (mean 5.8\%) patients with aortic stenosis that femoral-access TAVR had less mortality/morbidity, lower gradients, and shorter hospitalizations than surgical aortic valve replacements. ${ }^{2}$ Also, the SUrgical Replacement and Transcatheter Aortic Valve Implantation (SURTAVI) trial is making similar comparative

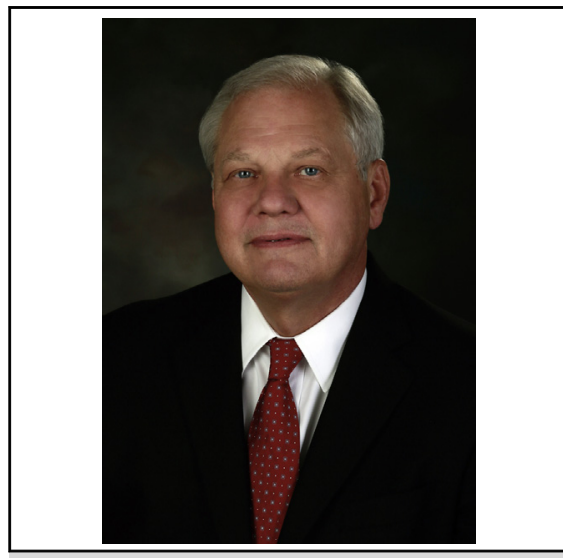

W. Randolph Chitwood, Jr, MD, FACS, FRCS (Eng), FACC

\section{Central Message}

Transcatheter mitral repair and replacement devices are in evolution. If this progress recapitulates that of transcatheter aortic valve replacement, an entire new horizon in mitral valve therapy lies ahead.

See Articles page 319 and 330.

See Editorial Commentary page 328.

assessments for patients with a mortality risk of between $3 \%$ and $15 \% .^{3}$ Moreover, the upcoming PARTNER III trial 